ISSN 1112-9867

http://www.jfas.info

\title{
TRIBOLOGICAL STUDY OF A BRONZE OBTAINED BY SINTERING PROCEEDS
}

\author{
F. Keraghel ${ }^{1, *}$, K. Loucif $^{1}$, M. P. Delplanck ${ }^{2}$ \\ ${ }^{1}$ Laboratoire des Matériaux non Métallique, Institut d'Optique et Mécanique de Précision, \\ Université Ferhat Abbas, Sétif 1, Algérie \\ ${ }^{2}$ Ecole Polytechnique de Bruxelles, Service 4 MAT Materials, Engineering, Characterization, \\ Synthesis \& Recycling,Université Libre de Bruxelles, Belgique
}

Received: 28 April 2016 / Accepted: 02 December 2016 / Published online: 01 January 2017

\begin{abstract}
Friction is a widely observed phenomenon requiring scientific capacity in the tribological behavior of materials. Reliability specialists use language borrowed from the doctors, so they talk about teething, durations of life and death, it is true that the machines as living beings, are born, wear, get tired, suffer defaults and eventually die; That is to say, are reformed, but the comparison stops, because the machines have no nervous system or bloodstream, do not think and feel no pain. Factors that may affect the life, or the factors that affect wear are very numerous: surface characteristics, operating conditions of the lubricant, the atmosphere, and finally the time. In this work we present the effect of speed and load on the tribological characteristics of a $\mathrm{Cu} 8 \% \mathrm{Sn}$ bronze pressure sintered self-lubricating mode for two lubricants with different viscosities.
\end{abstract}

Keywords: sintering; powder metallurgy; tribology; lubrication; copper alloy.

Author Correspondence, e-mail: f_keraghel@yahoo.fr doi: http://dx.doi.org/10.4314/jfas.v9i1.1 


\section{INTRODUCTION}

When two component parts of a mechanism are in relative motion relative to the other frictional forces arise at the level of their interface. These frictional forces depend on the bearing between the two bodies in contact, ie of all the forces which apply the one on the other and their relative moving speed. The density and porosity of the material that are a function of the development parameters (temperature, pressure and dwell time case of materials produced by the sintering process [1] also affect the damage mechanisms which depend on their turn a multitude factors [2]. The roughness of the contact surfaces can be torn; which is wear of the mechanism bodies. Moreover, this phenomenon is accompanied by a rise in temperature, which usually accelerates the wear of the parts. The heat generated in a mobile contact is the main form of this energy. Bayer [3] believes that the energy associated with the movement or surface damage are normally negligible in the open heat energy. In this case, the frictional force may have another shape. Today it is commonly accepted that the friction force is a contribution of adhesion energy and strain energy. The wear can be reduced by realizing the contact surfaces as smooth as possible, by grinding, lapping, or superfinishing. The self-lubrication or lubrication (porous materials soaked lubricants) [4]. also plays a very big role in interposing between the bodies surfaces a "third body" which, for example hydrodynamic regime; deviates these surfaces from each other and reduces or removes in some cases the wear phenomena. The selection of a lubricant depends on several criteria. Stachowiak [5] has presented a detailed study of the physical properties allowing the choice of a lubricant. Tribological and comparative study between mechanical $\mathrm{Cu}-10 \mathrm{Sn}$ bronze bushing and some metallic materials $(\mathrm{CuZn30}, \mathrm{ZnAl}, \mathrm{AlCuMg} 2$ and $\mathrm{SnPbCuSb})$ showed that the bronze is the best compromise between these alloys [6].

\section{2-EXPERIMENTAL METHOD}

\subsection{Material}

The material is a sintered bronze $\mathrm{Cu}-8 \mathrm{sn}$ pressure. Its density is about $70 \%$ to $80 \%$ of theoretical density. Porosity serves as a reservoir of oil for lubricity.

The samples studied are circular pellets of $6 \mathrm{~mm}$ diameter and $3 \mathrm{~mm}$ thick. 


\subsection{Device wear}

The device is formed of a hard steel cylinder mounted on the chuck of a horizontal lathe, and animated by a movement of rotation. The cylindrical sample is held by an arm on the blank of steel cylinder with perpendicular axes so as to ensure line contact. The contact force sample cylinder is provided by a weight at the end of the arm (Fig.1).
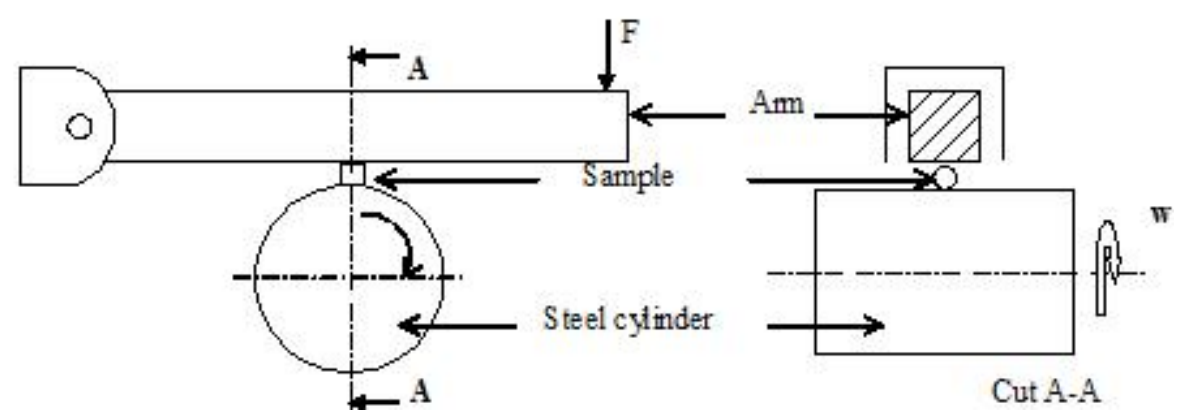

Fig.1. wear device

In this study, we followed the loss of size versus time for different sliding speed and contact forces of porous bronze $\mathrm{Cu}-8 \% \mathrm{Sn}$ obtained by pressurized sintering against hard teel 100Cr6 ring. Figure 2 shows the rating measure "e" du to loss of radial dimension. Tests are performed under 10 and $15 \mathrm{~N}$ and two kinds of lubricant: Tiska32 and Tiska68. The kinematic viscosity of lubricants is respectively 32 and 68 Cst.

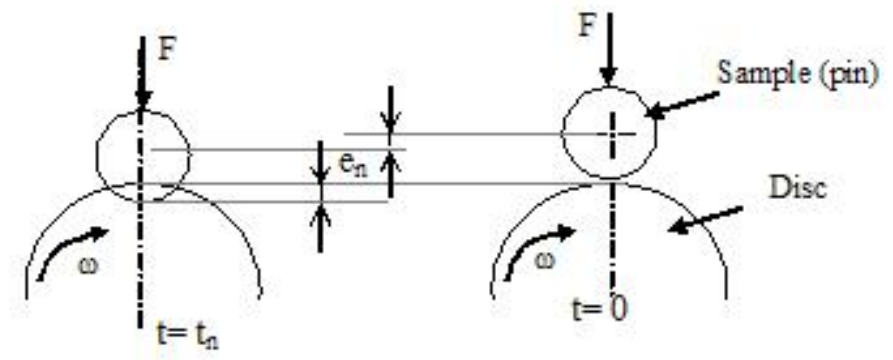

Fig.2. Principle of measurement

\section{RESULT AND DISCUSSION}

\subsection{General Description}

Figures 3 and 4 show the evolution of wear versus of time for different sliding speeds and for contact forces 10 and $15 \mathrm{~N}$, in contact mode lubricated (Tiska 32, Tiska 68). In general, the wear increases intermittently or stages and tends to an apparent stabilization for low forces. 
Figure 5 explain how variation of coast evolute versus time. Comparatively with conventional wear law, the loss of coast don't give a monotonous variation, but by stages. These stages depend on the speed, force and nature of the lubricant. Thus, we can say that the difference e (microns) does not increase monotonously but by jumping. This can be explained by the fact that the debris that detach samples are housed at the interface of opposing pieces and form a continuous layer of third body. This explains the maintenance of constant distance. Under the effect of cyclic contact layer, the latter then work-hardened compact and comes off the disc. This detachment results in a sudden loss of the coast and a clear break in the curve :

$$
e=f(t)
$$

We can also notice that when the sliding speed increases, the curves are shifted towards shorter durations. This is due to the activation process of training - hardening - detachment of the adhered layer. However, it marks the absence of stages in some cases (Fig. 3-a) or the superposition of stages under different conditions (Fig. 4-a). This makes it difficult to determine the conditions and parameters of adhering layer formation (third body) and rheology of debris in the contact.

We must add that for loads and high speeds, the curves do not tend toward stabilization, though, instead, to wear very strong (if $\mathrm{V}=1.25 \mathrm{~m} / \mathrm{s}, \mathrm{p}=15-20 \mathrm{~N}$ ). The general trend is in the form of Archard's equation $\left[\mathrm{V}_{\mathrm{a}}=\mathrm{K} . \mathrm{W} / \mathrm{H} . \mathrm{L}\right]$. This is certainly due to the experimental conditions (load and speed) exceeded the strength of the material.

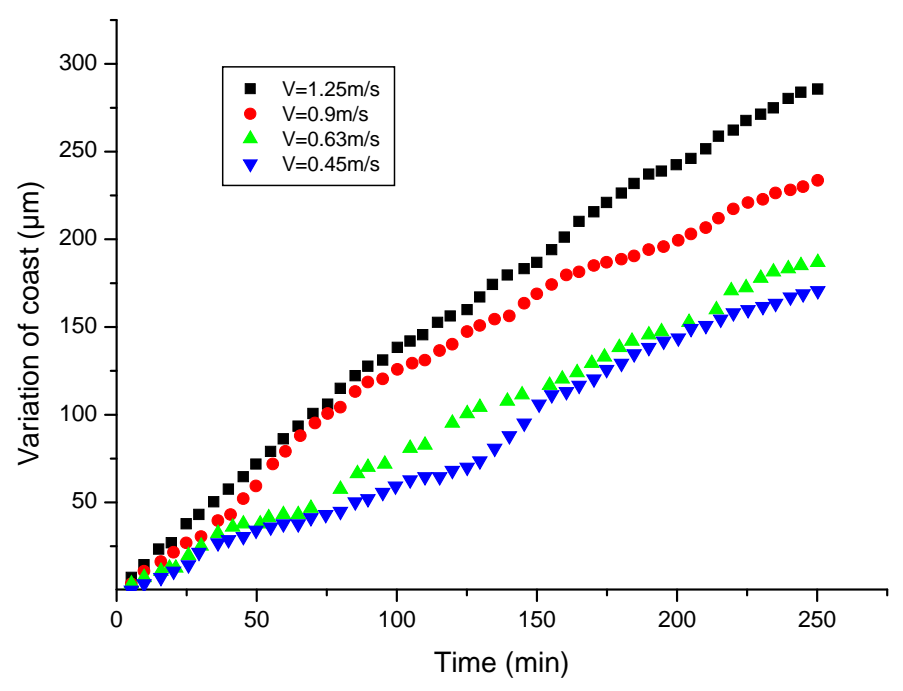


a - Force $10 \mathrm{~N}$

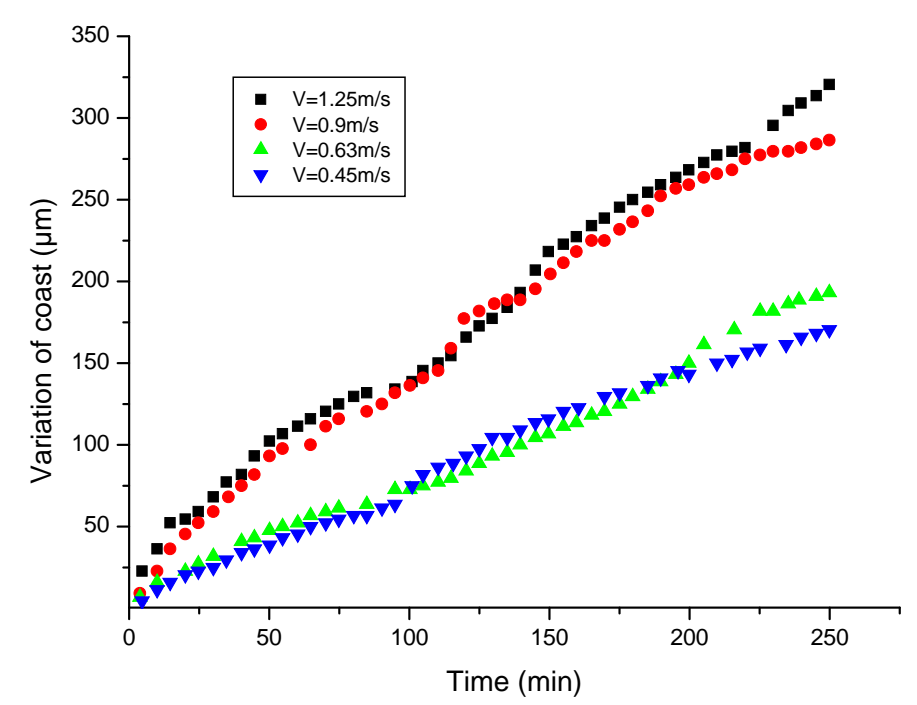

b - Force $15 \mathrm{~N}$

Fig.3. Evolution of the loss of coastline with time, case of Tiska 32 lubricant

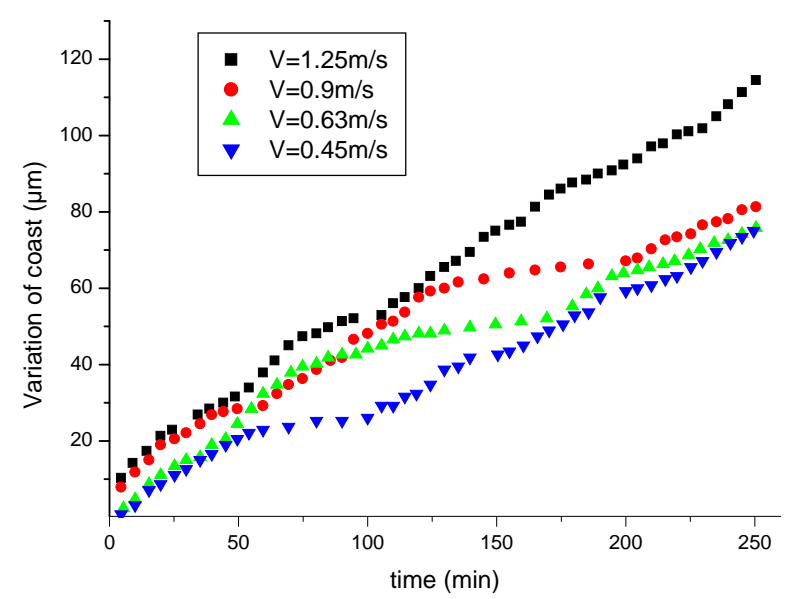

a - Force $10 \mathrm{~N}$ 


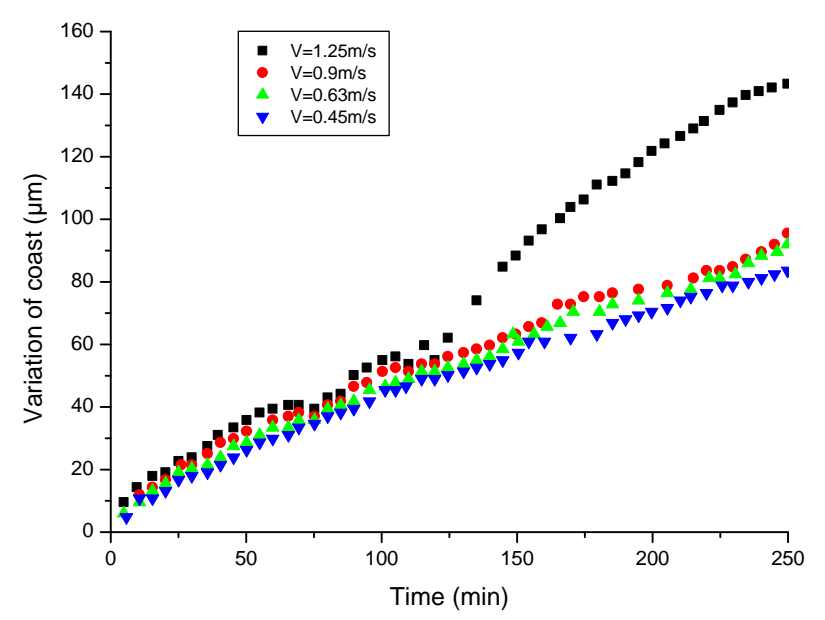

b - Force $15 \mathrm{~N}$

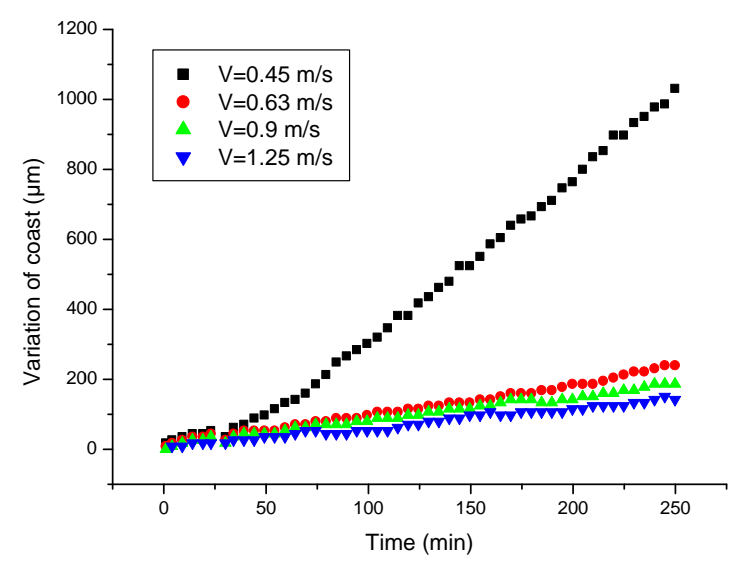

c-Load $20 \mathrm{~N}$

Fig.4. Evolution of the loss of coastline with time,case of Tiska 68 lubricant

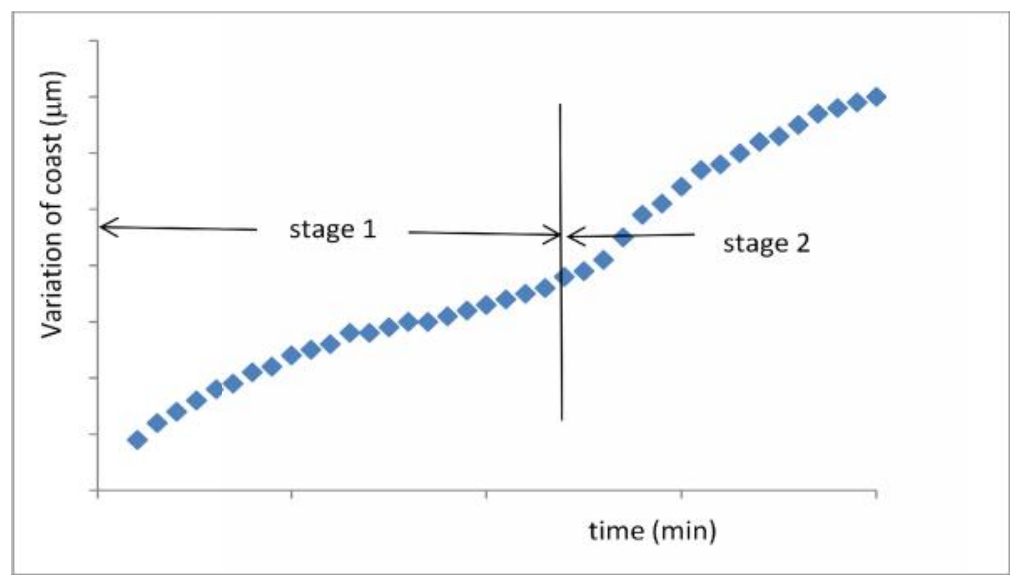

Fig.5. Kinematic evolution of variation of coat of samples versus time 


\subsection{Analysis and Interpretation}

\section{a- kinetic study}

For any force used, speed has an effect on the kinetics of the curves and not on their form. It is observed that the lifespan of formation of the adhered layers is reduced each time speed increases. That appears clearly for speed $1.25 \mathrm{~m} / \mathrm{s}$ and force $15 \mathrm{~N}$ for the two types of lubricant. The stages are reduced gradually until almost total disappearance. The curves tend towards a remarkable linearity.

Figure 6 gives times of appearance of the intermediate stages for force $10 \mathrm{~N}$. We chose this example because it presents the stages of evolution best. It is thus shown that the curves take hyperbolic forms according to the speed of slip. When the speed is low, the stage takes time to appear or to disappear, whereas for high speeds, the time of appearance becomes increasingly weak. The curves approach more and more (Fig. 6). This remark is valid for the two lubricants.

\section{b. Quantitative study}

\section{b.1. Effect of speed}

Figure 7 gives the amplitudes of the stages (intermediate stages) according to the speed of slip for a force $10 \mathrm{~N}$. We note generally that the amplitudes of the stages are appreciably equal regardless of sliding speed. It should be noted considerable coherence between the amplitudes of Tiska 68 oil than Tiska 32 oil. i.e. that the loss of east coast always the same one. That shows that the detachment of the layer of the third body is carried out after having reached a critical thickness, thickness able to separate from the steel cylinder. This observation goes in the same direction with the amplitudes of the various stages. 


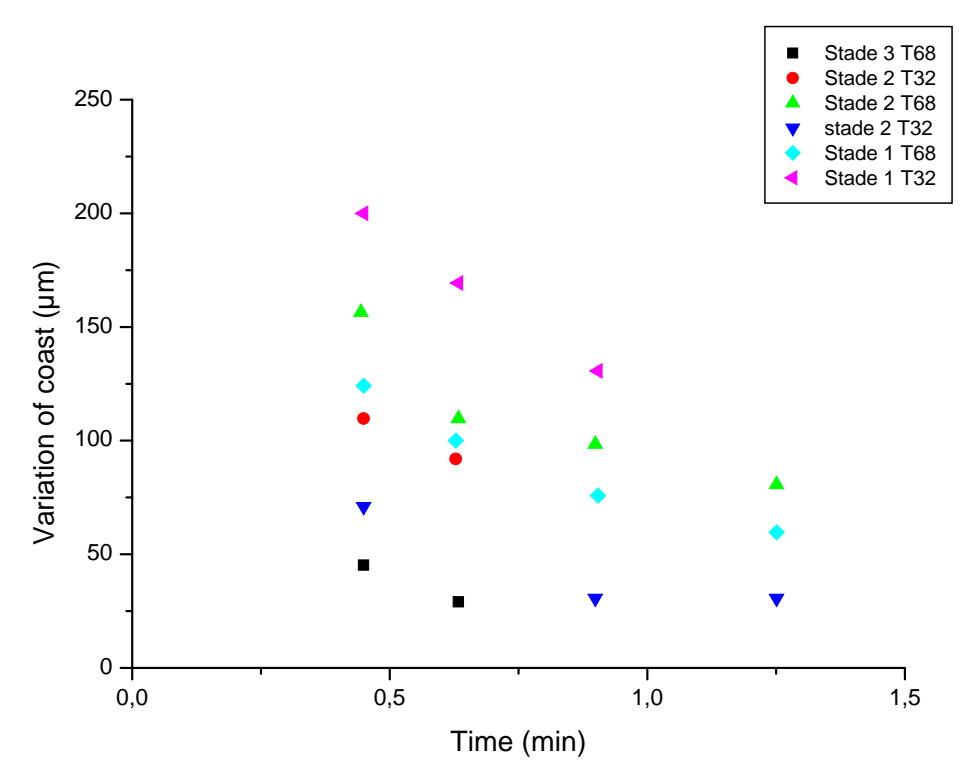

Fig.6. Time of appearance of the intermediate stages, for a force $10 \mathrm{~N}$

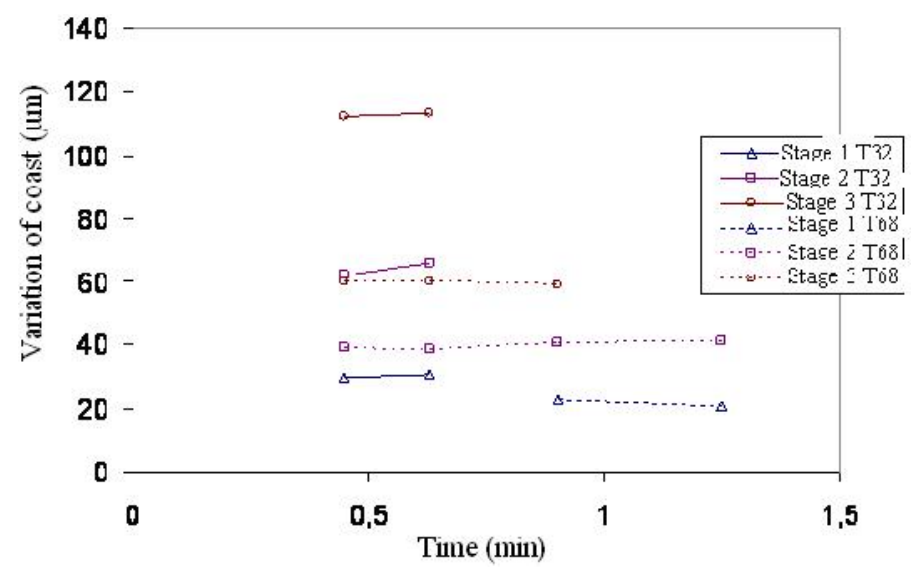

Fig.7. Cumulated amplitude of the stages under a force of $10 \mathrm{~N}$

Table 1 gives the amplitudes of the stages for the two types of lubricants.

Table 1. Amplitude of the intermediate stages

\begin{tabular}{lcc}
\hline & T68 & T32 \\
\hline Stage I & 15.21 & 15.21 \\
Stage II & 18.58 & 18.58 \\
Stage III & 11.14 & 11.14 \\
\hline
\end{tabular}

It is as possible to suppose as the delamination of the layer of the third body is carried out 
after having reached some physical properties such as hardening. At this level, this layer is considered as a proper element that detaches from the steel cylinder.

\section{b-2. Effect of the force}

According to figures 6 and 7, we can say that the effect of the force is similar to that speed. For the same speed, the curve shifts towards the left and sees its amplitude increasing when the force passes from a lower value $(10 \mathrm{~N})$ to a superior value $(15 \mathrm{~N}$ or $20 \mathrm{~N})$. In addition, clear obtaining the stages on the curves becomes less when the force increases. For example of the curves of wear with the Tiska 68 lubricant, the stages are well identified with the force $10 \mathrm{~N}$, lost in the general shape of the wear with 15 and disappeared completely with $20 \mathrm{~N}$.

These remarks are common to both lubricants. This let us conclude that when the force increases, the wear becomes severe, the debris will be shredded form. These conditions do not favor the formation of the third body layer.

\section{b-3. Effect of viscosity}

Figures 8 and 9 show respectively: the loss of coast increases with some instabilities versus time but we can't distinguish clearly stages and we give two general remarks:

- that the stages relating to the Tiska 32 lubricant appear before the stages relating to the Tiska 68 lubricant,

- that the amplitude of the stages relating to the Tiska 32 lubricant are larger with those of the stages relating to the T68 lubricant (seeTab.1) and this difference marks more and more that the speed of sliding increases. This is due to the effect of viscosity. As viscosity increases, the more wear decreases and the stages become increasingly slow. It seems that this slowness is due to the capacity of the lubricant to maintain the debris agglomerated like clusters. More the shear strength of the lubricant is important better the layers (cluster) adherent with the steel cylinder. 


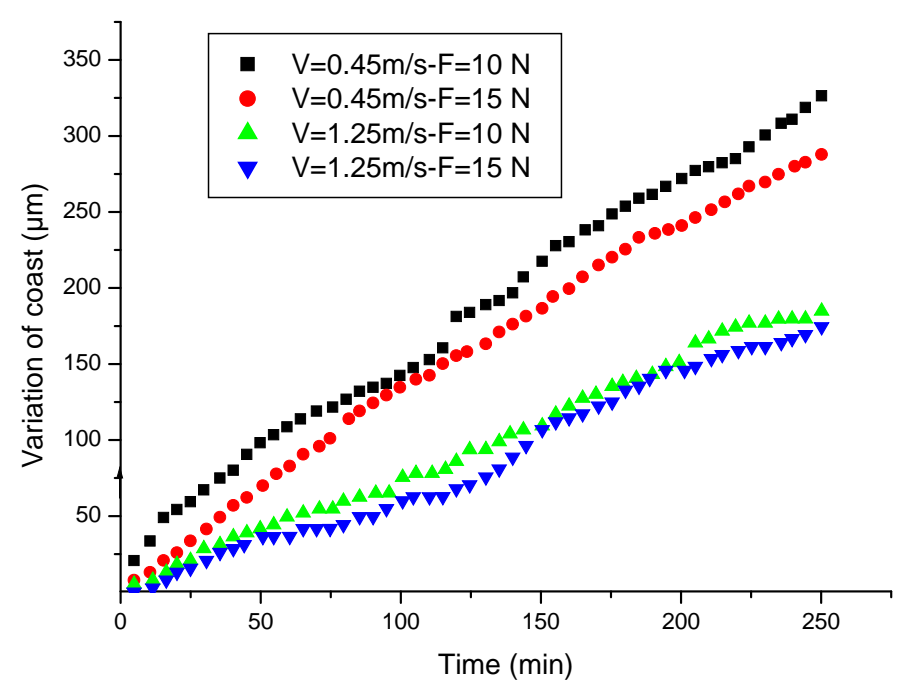

Fig.8. Evolution of the gap according to time for the Tiska32 lubricant

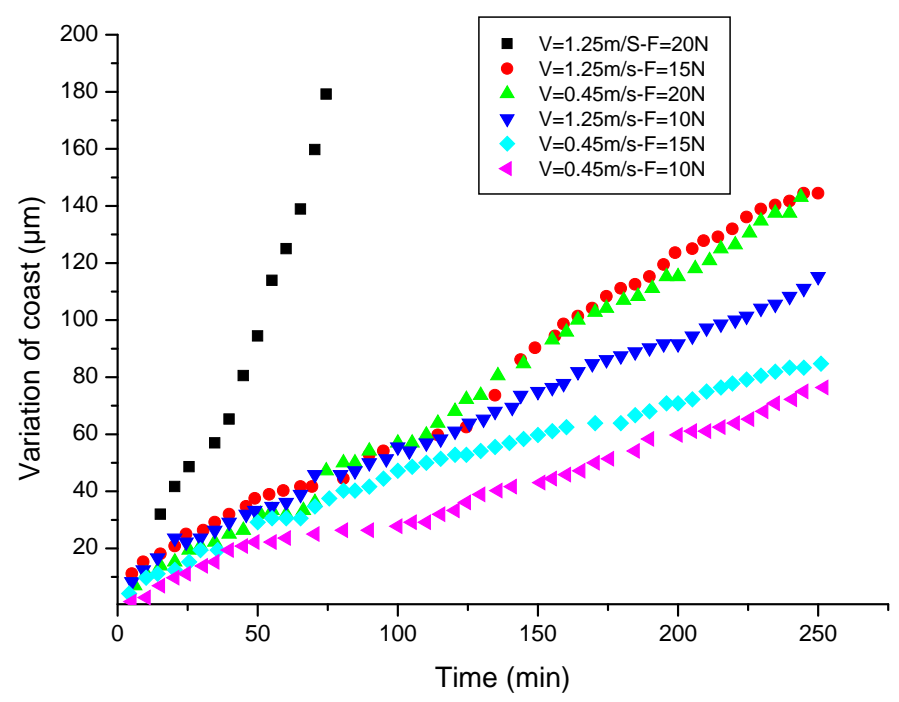

Fig.9. Evolution of the gap according to time for the Tiska 68 lubricant 


\section{CONCLUSION}

In the present work, we studied the effect of two lubricants (Tiska Tiska 32 and 68) on the wear of bronze $\mathrm{Cu}-8 \% \mathrm{Sn}$ under pressure with sintered steel Z200C13 for different sliding speeds and different contact forces 10-20 N, in lubricated contact mode. It is announced that the tests were performed on a device of wear assembled on a universal lathe.

The results obtained enabled us to conclude that:

a- wear occurs in a discontinuous manner not in a monotonous manner,

b- the stages of wear disappear as the force and/or speed increase,

c- the amplitudes of the stages are approximately equal regardless of sliding speed for the load $10 \mathrm{~N}$ and see their amplitudes increase when going from a lower force $(10 \mathrm{~N})$ at a higher force $(15-20 \mathrm{~N})$,

d- more viscosity increases more wear decreases and the stages become increasingly slow,

In prospect, a work concerning the analysis of the debris deserves

\section{ACKNOWLEDGEMENTS}

I want to thank Mr. Manaa for providing good language help

\section{REFERENCES}

[1] Jabur A. S., Effect of powder metallurgy conditions on the properties of porous bronze, Powder Technology 237 (2013) pp. 477-483

[2] Descartes S., Berthier Y., Rheology and flows of solid third bodies: background and application to an $\mathrm{MoS}_{1.6}$ coating, Wear V252, N7-8 (2002) pp.546-556

[3] Bayer R.G., Mechanical wear fundamentals and testing, éd. Marcel Dekker New-York (2004) $393 p$

[4] Nelis M., Optimisation théorique et expérimentale du régime autolubrifiant des paliers poreux, Thèse de doctorat, Université de Liège Belgique (2000) 191p

[5] Stachowiak G.W., Batchelor A.W., Engineering tribology, éd. Butterworth Heinemann Sidney (2005) 801p 
[6] Ünlü B.S., Investigation of tribological and mechanical properties of metal bearings, Bull. Mater. Sci., Vol. 32, N4 (August 2009) pp. 451-457

How to cite this article:

Keraghel F, Loucif K, Delplanck M. P. Tribological study of a bronze obtained by sintering proceeds. J. Fundam. Appl. Sci., 2017, 9(1), 1-12. 